\title{
PERANAN FIELD OFFICER PT VASHAM KOSA SEJAHTERA DALAM PROGRAM KEMITRAAN DENGAN PETANI JAGUNG DI KECAMATAN KETAPANG KABUPATEN LAMPUNG SELATAN
}

\author{
(Role of Field Officers at PT Vasham Kosa Sejahtera in Partnership Program with Corn Farmers \\ in Ketapang Subdistrict South Lampung Regency)
}

Imam Sugiharto Dermawan, Irwan Efendi, Kordiana K Rangga

\begin{abstract}
Jurusan Agribisnis, Fakultas Pertanian,Universitas Lampung, Jl. Prof. Dr. Soemantri Brodjonegoro No.1 Bandar Lampung 35145, Telp.081372858586,e-mail: Imamsugihartodermawan@gmail.com
\end{abstract}

\begin{abstract}
This study aims to determine the partnership patterns that are applied and analyze the roles of facilitators in partnership programs, the relationship between the roles of the facilitators and the productivity of farmer partners, the relationship between production and income of farmer partners, and the differences in productivity and income of farmer partners of PT Vasham Kosa Sejahtera and non-partners. This location was chosen purposively with consideration that South Lampung Regency is the largest corn production center in Lampung Province and Ketapang District, where there are most partner farmers of PT Vasham Kosa Sejahtera in South Lampung Regency. Respondents were 50 partner farmers and 50 non-partner farmers. This research method uses a survey method, descriptive analysis and rank Spearman correlation test. The results showed that the partnership pattern that was established with partner corn farmers belonged to the pattern of Agribusiness Operational Cooperation (KOA). The role of Field Officers PT Vasham Kosa Sejahtera in the partnership program as a whole is quite a role. There is no significant relationship beetwen role of field officer and productivity of partner farmer corn farming. There is significant relationship between production and income of partner farmers corn farming. There is diferenece productivity of partner farmers and non-partner farmers corn farming and no difference between income of partner farmers and non-partner farmers corn farming.
\end{abstract}

Key words: corn farming, facilitators, farmers, partnerships, roles

\section{PENDAHULUAN}

Indonesia merupakan negara agraris dengan ribuan pulau yang mempunyai potensi besar dalam pengembangan di sektor pertanian. Pengembangan di sektor pertanian diarahkan untuk meningkatkan produksi pertanian guna memenuhi kebutuhan pangan dan kebutuhan industry dalam negri meningkatkan ekspor, meningkatkan pendapatan petani, memperluas kesempatan kerja dan mendorong pemerataan kesempatan berusaha (Soekartawi 2003).

Tanaman pangan merupakan bagian penting yang tidak terpisahkan dari sektor pertanian. Khusus di Indonesia, tanaman pangan juga berkedudukan strategis dalam memelihara stabilitas ekonomi nasional. Jagung merupakan salah satu komoditas utama tanaman pangan yang mempunyai peranan strategis dalam pembangunan pertanian dan perekonomian Indonesia, mengingat komoditas ini mempunyai fungsi multiguna, baik untuk konsumsi langsung maupun sebagai bahan baku utama industri pakan. Pada Tahun 2015 Provinsi
Lampung merupakan salah satu daerah penghasil jagung terbesar kelima di Indonesia yaitu sebesar 1.502.800 ton dengan luas lahan 339.308 ha dan produktivitas sebesar 5,12 ton/ha (BPS 2016).

Lampung Selatan pada tahun 2015 merupakan salah satu daerah sentra produksi jagung, dengan produksi paling tinggi yaitu sebesar 563.732 ton, luas tanam lahan 110.201 ha dan produktivitasnya cukup tinggi yaitu sebesar 5,1 ton/ha. Jumlah produksi yang dihasilkan berasal dari seluruh desa yang ada pada Kecamatan Lampung Selatan. Kecamatan Ketapang merupakan daerah yang memiliki total produksi keempat setelah Penengahan, Kalianda, dan Natar, yaitu sebesar 53.875 ton dengan luas panen sebesar 10.532 ha. Meskipun jika dilihat segi produktivitas Kecamatan Ketapang masih tergolong rendah, yaitu hanya sebesar 5.11 ton/ha. Hal ini karena adanya keterbatasan petani dalam modal, teknologi, dan sumberdaya manusia perlu dilakukannya upaya agar produksi terus bertambah dan produktivitas semakin meningkat. Salah satu upaya dalam pengembangan jagung di Lampung 
Selatan, terutama di kecamatan Ketapang adalah dengan mengikuti kemitraan untuk membantu petani dalam penyediaan input

dan proses pemasaran yang lebih mudah. Salah satu perusaahan yang bergerak di bidang kemitraan adalah PT Vasham Kosa Sejahtera.

Keberhasilan program kemitraan yang dilakukan oleh PT Vasham Kosa Sejahtera tidak terlepas dari peranan Field Officer (FO)/fasilitator pendamping. Pendampingan berarti bantuan dari pihak luar, baik perorangan maupun kelompok untuk menambahkan kesadaran dalam rangka pemenuhan kebutuhan dan pemecahan permasalahan kelompok. Melihat dari pengertian di atas, peran fasilitator pada perusahaan PT Vasham Kosa Sejahtera seharusnya mampu memberikan peningkatan pada produktivitas jagung petani mitra.

Hal tersebut yang melatarbelakangi untuk dilaksanakannya penelitian lebih mendalam mengenai peranan FO PT Vasham Kosa Sejahtera dalam program kemitraan petani jagung. Berdasarkan uraian tersebut penelitian ini bertujuan untuk mengetahui pola kemitraan yang diterapkan, mengetahui peran fasilitator dalam program kemitraan, menganalisis hubungan antara peranan Fasilitator dengan produktivitas usahatani petani jagung mitra, menganalisis hubungan antara produksi dan pendapatan usahatani petani jagung mitra serta mengetahui perbedaan produktivitas serta pendapatan usahatani jagung antara petani mitra PT Vasham Kosa Sejahtera dengan petani jagung non mitra di Kecamatan Ketapang Kabupaten Lampung Selatan .

\section{METODE PENELITIAN}

Lokasi penelitian di Kecamatan Ketapang Kabupaten Lampung Selatan. Penentuan lokasi dilakukan secara sengaja (purposive) dengan pertimbangan Kabupaten Lampung Selatan merupakan daerah sentra produksi jagung terbesar di Lampung, dan Kecamatan Ketapang terdapat petani mitra Vasham terbanyak. Responden penelitian yakni perwakilan petani jagung yang mengikuti program kemitraan dari masing-masing KKV di PT Vasham Kosa Sejahtera, dan perwakilan petani jagung yang tidak mengikuti program kemitraan di Kecamatan Ketapang Kabupaten Lampung Selatan. Responden dipilih secara acak (simple random sampling). Sampel penelitian ini berjumlah 50 responden petani jagung yang mengikuti program kemitraan PT Vasham Kosa Sejahtera dengan populasi sebesar
625 orang petani jagung. Penentuan jumlah sampel mengacu pada Sugiarto (2003).

$\mathrm{n}=\frac{\mathrm{NZ}^{2} \mathrm{~S}^{2}}{\mathrm{Nd}^{2}+\mathrm{Z}^{2} \mathrm{~S}^{2}}$

Keterangan:

$\mathrm{n}=$ Jumlah sampel

$\mathrm{N}=$ Jumlah anggota dalam populasi (625)

$\mathrm{Z}=$ Derajat kepercayaan $(90 \%=1,64)$

$S^{2}=$ Varian sampel $(5 \%)$

$\mathrm{D}=$ Derajat penyimpangan $(5 \%)$

Metode yang digunakan dalam penelitian ini adalah metode survei. Data yang digunakan dalam penelitian ini meliputi data primer dan data sekunder. Data primer diperoleh melalui hasil wawancara langsung. Data sekunder diperlukan sebagai tambahan informasi yang diperoleh dari literatur, dinas atau instansi terkait dan lembagalembaga yang berhubungan dengan penelitian ini. Analisis data yang digunakan dalam penelitian ini menggunakan metode deskriptif kuantitatif, sedangkan pengujian hipotesis menggunakan analisis statistik non parametrik uji korelasi rank Spearman (Siegel 2011) dengan bantuan SPSS 22.

\section{HASIL PENELITIAN}

\section{Pola Kemitraan PT Vasham Kosa Sejahtera}

Bentuk kemitraan dalam sistem agribisnis menurut Sumardjo (2004) yaitu pola kemitraan inti plasma, pola kemitraan subkontrak, pola kemitraan dagang umum, pola kemitraan keagenan, pola kemitraan KOA (kerjasama operasional agribisnis). Pola kemitraan KOA merupakan hubungan bisnis yakni kelompok mitra menyediakan lahan, sarana dan tenaga kerja, sedangkan perusahaan mitra menyediakan modal, biaya, manajemen dan pengadaan sarana produksi untuk budidaya suatu komoditas pertanian.

PT Vasham selaku pihak pertama adalah produsen yang menyediakan modal dan saprotan kepada petani mitra. Saprotan yang diperoleh dari PT Vasham Kosa Sejahtera selanjutnya dikembangkan dan dibudidayakan oleh petani mitra selaku pihak kedua dibantu dengan pihak perusahaan. Konsep kemitraan yang dijalankan oleh PT Vasham Kosa Sejahtera digolongkan ke dalam pola Kerjasama Operasional Agribisnis. 


\section{Tingkat Peranan FO dalam Program Kemitraan oleh PT Vasham Kosa Sejahtera (Variabel X)}

Tabel 1 menunjukkan bahwa peranan Fasilitator dilihat dari fungsi atau tugas yang terdapat pada indikator sebagai Fasilitator, yaitu dalam melakukan edukasi, diseminasi informasi, fasilitasi, konsultasi, dan pemantauan. Sebagaimana mestinya yaitu fasilitator berfungsi untuk membantu petani dalam meningkatkan pengetahuan petani tentang program kemitraan dan membina petani dalam proses berusahatani.

Peranan Fasilitator dilihat dari fungsi atau tugas yang terdapat pada indikator sebagai Fasilitator, yaitu dalam melakukan edukasi, diseminasi informasi, fasilitasi, konsultasi, dan pemantauan. Sebagaimana mestinya yaitu Fasilitator berfungsi untuk membantu petani dalam meningkatkan pengetahuan petani tentang program kemitraan dan membina petani dalam proses berusahatani. Peranan FO dalam menjalankan perannya sebagai edukasi sudah cukup baik, FO mengetehui seluruh program kemitraan oleh PT. Vasham Kosa Sejahtera.

Penyuluhan yang diberikan oleh FO tidak hanya materi atau teori saja tapi juga memberitahu praktekannya kepada petani, serta memberikan pelatihan dan pendampingan dalam berusahatani Peranan FO dalam program kemitraan PT Vasham Kosa Sejahtera secara keseluruhan masuk ke dalam klasifikasi sedang. Hal ini dikarenakan masih terdapat beberapa kendala dalam menjalankan perannya disetiap indikator yang menyebabkan FO belum mampu melaksanakan perannya dalam melakukan kegiatan program kemitraan PT Vasham Kosa Sejahtera secara maksimal.

Tabel 1. Peranan FO dalam program kemitraan PT Vasham Kosa Sejahtera

\begin{tabular}{cccc}
\hline $\begin{array}{c}\text { Peranan FO } \\
\text { dalam } \\
\text { Program } \\
\text { Kemitraan }\end{array}$ & Klasifikasi & $\begin{array}{c}\text { Jumlah } \\
\text { Responden } \\
\text { (orang) }\end{array}$ & $\begin{array}{c}\text { Persentase } \\
(\%)\end{array}$ \\
\hline $26,61-32,03$ & Rendah & 15 & 30 \\
$32,04-37,46$ & Sedang & 23 & 46 \\
$37,47-42,90$ & Tinggi & 12 & 24 \\
\hline Jumlah & & 50 & 100 \\
\hline Rata-rata & 34,57 & & \\
\hline
\end{tabular}

Tabel 2. Klasifikasi indikator peranan fasilitator dalam program PT Vasham Kosa Sejahtera

\begin{tabular}{cll}
\hline No. & \multicolumn{1}{c}{ Indikator } & $\begin{array}{c}\text { Klasifikasi } \\
\text { (rata-rata) }\end{array}$ \\
\hline 1. & Edukasi & Sedang $(7,88)$ \\
2. & Diseminasi Informasi & Sedang $(7,05)$ \\
3. & Fasilitasi & Sedang $(8,42)$ \\
4. & Konsultasi & Sedang $(6,22)$ \\
5. & Pemantauan & Sedang $(4,99)$ \\
\hline
\end{tabular}

Hubungan Antara Peranan Fasilitator PT Vasham Kosa Sejahtera dengan Tingkat Produktivitas jagung petani mitra PT Vasham Kosa Sejahtera di Kecamatan Ketapang Kabupaten Lampung Selatan

Produktivitas jagung merupakan salah satu tujuan utama atau hasil akhir yang diinginkan petani mitra. Produktivitas yang besar berpengaruh terhadap pendapatan yang diterima petani jagung.. Berbagai cara termasuk memperbaiki fasilitas sarana dan prasarana, cara budidaya dan sebagainya telah dilakukan untuk meningkatkan produktivitas jagung. Tabel 3 menunjukkan bahwa produktivitas usahatani jagung petani mitra berada pada klasifikasi rendah sebanyak 3 orang (6\%), produktivitas usahatani jagung petani mitra berada pada klasifikasi sedang 28 orang $(56 \%)$ produktivitas usahatani jagung petani mitra berada pada klasifikasi tinggi 19 orang (38\%).

Hubungan antara peranan FO terhadap produktivitas usahatani petani jagung mitra PT Vasham Kosa Sejahtera diperoleh nilai signifikansi yaitu sebesar 0,329 lebih besar dari $\alpha(0,05)$ pada taraf kepercayaan 95\%. Artinya peranan FO tidak mempunyai hubungan yang siginifikan dengan produktivitas usahatani petani jagung mitra dalam program kemitraan PT Vasham Kosa Sejahtera di Kecamatan Ketapang Kabupaten Lampung Selatan.

Tabel 3. Klasifikasi produktivitas usahatani jagung petani mitra per musim

\begin{tabular}{cccc}
\hline $\begin{array}{c}\text { Produktivitas } \\
\text { Usahatani } \\
\text { Jagung (kg/ha) }\end{array}$ & Klasifikasi & $\begin{array}{c}\text { Jumlah } \\
\text { Responden } \\
\text { (Orang) }\end{array}$ & $\begin{array}{c}\text { Persentase } \\
(100 \%)\end{array}$ \\
\hline $4.000-5.533$ & Rendah & 3 & 6 \\
$5.534-7.067$ & Sedang & 28 & 56 \\
$7.068-8.600$ & Tinggi & 19 & 38 \\
\hline Jumlah & & 50 & 100 \\
\hline Nilai Rata-rata & 6.685 kg/ha & & \\
\hline
\end{tabular}


Berdasarkan hasil penelitian di lapangan bahwa jumlah FO tidak sebanding dengan banyaknya jumlah petani yag mengikuti program kemitraan. Hal ini menunjukkan bahwa peranan FO belum mampu memberikan kontribusi yang nyata terhadap produktivitas petani jagung mitra.

Hasil penelitian ini sesuai dengan hasil penelitian Nurjanah (2012) mengenai Kinerja Penyuluh Pertanian Lapangan (PPL) dan Produktivitas Usahatani Padi di Kabupaten Tanggamus diperoleh tidak ada hubungan yang nyata antara kinerja PPL di BP3K dengan produktivitas padi diwilayah kerja BP3K. Hal ini menunjukkan bahwa kinerja PPL di BP3K belum memberikan kontribusi yang nyata terhadap tingkat produktivitas padi di wilayah kerja BP3K.

\section{Hubungan antara Produksi usahatani jagung dengan pendapatan usahatani jagung petani mitra PT Vasham Kosa Sejahtera}

Tabel 4 menunjukkan bahwa produksi usahatani jagung petani mitra berada pada klasifikasi rendah sebanyak 3 orang (6\%), produksi usahatani jagung petani mitra berada pada klasifikasi sedang 28 orang $(56 \%)$ produksi usahatani jagung petani mitra berada pada klasifikasi tinggi 19 orang (38\%). Nilai rata-rata skor yang didapat dari hasil data lapangan produksi usahatani jagung petani mitra masuk dalam klasifikasi sedang yaitu sebesar $6.685 \mathrm{~kg} / \mathrm{ha}$.

Hasil penelitian menunjukkan bahwa produksi memiliki hubungan dengan pendapatan petani. Menurut Rahim dan Diah (2008), ketika produksi yang dihasilkan oleh petani rendah maka pendapatan yang didapatkan oleh petani jagung akan rendah juga, tetapi tergantung dari harga jual, bila harga dan produksi berubah maka pendapatan yang diterima petani juga berubah karena harga dan produksi merupakan salah satu faktor yang mempengaruhi pendapatan.

Tabel 4. Klasifikasi produksi usahatani jagung petani mitra per musim.

\begin{tabular}{cccc}
\hline $\begin{array}{c}\text { Produksi } \\
\text { Usahatani } \\
\text { Jagung (kg/ha) }\end{array}$ & Klasifikasi & $\begin{array}{c}\text { Jumlah } \\
\text { Responden } \\
\text { (Orang) }\end{array}$ & $\begin{array}{c}\text { Persentase } \\
(100 \%)\end{array}$ \\
\hline $4.000-5.533$ & Rendah & 3 & 6 \\
$5.534-7.067$ & Sedang & 28 & 56 \\
$7.068-8.600$ & Tinggi & 19 & 38 \\
\hline Jumlah & & 50 & 100 \\
\hline Nilai Rata-rata & 6.685 kg/ha \\
& $($ Sedang) & & \\
\hline
\end{tabular}

Tabel 5. Klasifikasi pendapatan usahatani jagung petani mitra per musim.

\begin{tabular}{ccc}
\hline $\begin{array}{c}\text { Pendapatan Usahatani } \\
\text { Jagung (Rp/ha) }\end{array}$ & Klasifikasi & $\begin{array}{c}\text { Persentase } \\
(100 \%)\end{array}$ \\
\hline $1.570 .455,00-3.720 .745,00$ & Rendah & 24 \\
$3.720 .746,00-5.871 .036,00$ & Sedang & 36 \\
$5.871 .037,00-8.021 .325,00$ & Tinggi & 40 \\
\hline Jumlah & & 100 \\
\hline Nilai Rata-rata & Rp $5.329 .541,07$ (Sedang) \\
\hline
\end{tabular}

Pendapatan usahatani merupakan hasil pengurangan dari total penerimaan usahatani dengan total biaya yang dikeluarkan. Pendapatan usahatani menggambarkan keadaan sekarang dari suatu usahatani sehingga dapat melakukan evaluasi dengan peranan dan tindakan pada masa yang akan datang.

Tabel 5 menunjukkan bahwa sebanyak 12 orang (24\%) pendapatan usahatani petani jagung yang mengikuti program kemitraan masuk ke dalam klasifikasi rendah, sebanyak 18 orang (36\%) masuk ke dalam klasifikasi sedang dan sebanyak 20 orang (40\%) masuk ke dalam klasifikasi tinggi. Rata-rata pendapatan petani jagung dengan jumlah responden sebanyak 50 orang yang mengikuti program kemitraan PT Vasham Kosa Sejahtera sebesar Rp5.329.541,07 atau termasuk dalam klasifikasi sedang. Hasil pengujian statistik tersebut menunjukan bahwa produksi usahatani petani jagung mitra memiliki hubungan yang tidak nyata dengan pendapatan usahatani petani jagung mitra.

Pengujian statistik hubungan antara produksi dan pendapatan usahatani jagung petani mitra PT Vasham Kosa Sejahtera menunjukkan nilai signifikansi yaitu 0,01 lebih kecil dari $\alpha(0,05)$ pada taraf kepercayaan $95 \%$, maka dapat diambil keputusan untuk menerima H1. Artinya produksi usahatani jagung petani mitra mempunyai hubungan yang siginifikan dengan pendapatan usahatani petani jagung mitra dalam program kemitraan PT Vasham Kosa Sejahtera di Kecamatan Ketapang Kabupaten Lampung Selatan.

\section{Perbedaan produktivitas dan pendapatan antara petani mitra dan non mitra}

Pendapatan usahatani jagung petani mitra didapat dari penerimaan total dikurang dengan seluruh biaya, termasuk modal pinjaman dari PT Vasham Kosa Sejahtera dan setelah dikurang dengan bagi hasil antara petani dan perusahaan yaitu $90 \%$ untuk petani dan $10 \%$ untuk PT Vasham Kosa 
Sejahtera, sedangkan untuk pendapatan usahatani jagung petani non mitra hanya dari jumlah penerimaan dikurang dengan seluruh biaya, pendapatan yang digunakan pendapatan total perhektar.

a) Rata-rata produktivitas usahatani jagung petani mitra yaitu $6.684,66 \mathrm{~kg} / \mathrm{ha} / \mathrm{musim}$ lebih tinggi dari produktivitas petani non mitra yaitu 6.043,66 kg/ha/musim. Berdasarkan hasil uji beda $\mathrm{t}$ pendapatan usahatani jagung petani mitra dan non mitra dengan bantuan program SPSS 22 diperoleh nilai sig (2-tailed) sebesar 0,07. Sesuai dengan kaidah pengambilan keputusan, jika nilai sig (2-tailed) $<0,10$ menunjukkan bahwa terima $\mathrm{H} 1$, tolak Ho yang berarti terdapat perbedaan yang nyata pada data produktivitas petani mitra dan non mitra dengan tingkat kepercayaan sebesar $90 \%$.

b) Rata-rata pendapatan usahatani jagung petani mitra yaitu Rp5.329.541,07/ha/musim lebih tinggi dari pendapatan usahatani jagung petani non mitra yaitu Rp5.106.720,11/ha/musim. Berdasarkan uji beda $t$ dengan bantuan program SPSS 22 diperoleh nilai sig (2-tailed) sebesar 0,466. Sesuai dengan kaidah pengambilan keputusan, jika nilai sig (2-tailed) > 0,10 menunjukkan bahwa terima Ho, tolak H1 yang berarti tidak terdapat perbedaan yang nyata pada data pendapatan usahatani jagung petani mitra dan pendapatan usahatani jagung petani non mitra dengan tingkat kepercayaan sebesar $90 \%$.

Rata -rata produktivitas usahatani jagung dan pendapatan usahatani jagung petani mitra lebih tinggi dibandingkan dengan produktivitas usahatani jagung dan pendapatan usahatani jagung petani non mitra, tetapi berdasarkan hasil uji beda-t menunjukkan bahwa tidak terdapat perbedaan yang signifikan. Hal ini dikarenakan rata-rata produktivitas usahatani jagung dan pendapatan usahatani jagung antara petani mitra dan non mitra tidak terlalu berbeda jauh, namun disisi lain, petani yang mengikuti program kemitraan mendapat hal lain yang bermanfaat seperti pinjaman modal berupa saprotan dan pemasaran hasil panen.

\section{KESIMPULAN}

Berdasarkan hasil penelitian tentang peranan Field Officer PT Vasham Kosa Sejahtera dalam program kemitraan dengan petani jagung di Kecamatan Ketapang Kabupaten Lampung Selatan, maka dapat disimpulkan bahwa pola kemitraan yang dijalankan oleh PT Vasham Kosa Sejahtera tergolong ke dalam pola Kerjasama Operasional Agribisnis (KOA), peranan FO PT Vasham Kosa Sejahtera dalam program kemitraan masuk ke dalam klasifikasi sedang (cukup berperan). Hubungan antara peranan $F O$ PT Vasham Kosa Sejahtera dengan produktivitas usahatani jagung petani mitra yakni tidak terdapat hubungan yang nyata, terdapat hubungan yang nyata antara produksi usahatani jagung petani mitra dengan pendapatan usahatani jagung petani mitra, terdapat perbedaan antara produktivitas usahatani jagung petani mitra dan non mitra bebeda, tidak terdapat perbedaan antara pendapatan usahatani jagung petani mitra dan non mitra.

\section{DAFTAR PUSTAKA}

BPS [Badan Pusat Statistik]. 2016. Indonesia dalam Angka Tahun 2015. Jakarta.

Soekartawi. 2003. Prinsip Ekonomi Pertanian. Rajawali Press. Jakarta.

Sugiarto, Siagian D, Sunaryanto LT dan Oetomo DS. 2003. Teknik Sampling. PT Gramedia Pustaka Utama. Jakarta.

Sumardjo. 2004. Teori dan Praktek Kemitraan Agribisnis. Penebar Swadaya. Jakarta.

Siegel S. 2011. Statistik Non Parametrik Untuk Ilmu-Ilmu Sosial. Gramedia. Jakarta.

Nurjanah. 2012. Kinerja Penyuluh Pertanian Lapangan (PPL) dan Produktivitas Usahatani Padi di Kabupaten Tanggamus. Skripsi. Universitas Lampung. Lampung.

Rahim ABD dan Diah RDH. 2008. Ekonomika Pertanian (Pengantar, Teori, dan Kasus). Penebar Swadaya. Jakarta.

PT Vasham Kosa Sejahtera Kecamatan Ketapang. 2016. Data dan Informasi Field Officer dan Petani Mitra PT Vasham Kosa Sejahtera. Lampung Selatan. 